\title{
Favorable response to doxorubicin combination chemotherapy does not yield good clinical outcome in patients with metastatic breast cancer with triple-negative phenotype
}

Seong Yoon $\mathrm{Yi}^{1}$, Jin Seok Ahn ${ }^{*}$, Ji Eun Uhm ${ }^{1}$, Do Hyoung Lim ${ }^{1}$, Sang Hoon Ji ${ }^{1}$, Hyun Jung Jun ${ }^{1}$, Kyoung Ha Kim', Myung Hee Chang ${ }^{1}$, Min Jae Park', Eun Yoon Cho², Yoon La Choi' , Yeon Hee Park', Young-Hyuck Im

\begin{abstract}
Background: We analyzed the responses to first line treatment and clinical outcomes of metastatic breast cancer patients treated with palliative doxorubicin/cyclophosphamide (AC) according to molecular cancer subtype.

Methods: A retrospective analysis was performed for 110 metastatic breast cancer patients selected on the basis of palliative AC treatment and the availability of immunohistochemical data for estrogen receptor (ER), progesterone receptor (PR), and human epidermal growth factor receptor-2 (HER-2/neu) status.

Results: Of the 110 patients analyzed, 71 (64.5\%) were hormone receptor positive (HR+), 14 (12.7\%) were HER2+, and 25 (22.7\%) were triple negative (TN). There were no differences in age, stage at diagnosis, total number of cycles of palliative chemotherapy, incidence of visceral metastasis, and metastatic sites with the exception of liver among breast cancer subtypes. The overall response rates to AC were $55.9 \%$ for the HR+ subgroup, $42.9 \%$ for the HER2+ subgroup, and $56.5 \%$ for the TN subgroup. The progression-free survival (PFS) in patients with HER2+ and TN were significantly shorter than in the HR+ (median PFS, 9.1 vs 8.1 vs 11.5 months, respectively; $p=0.0002$ ). The overall survival (OS) was 25.4 months in the TN subgroup and 27.3 months in HER2+ subgroup. The median OS for these two groups was significantly shorter than for patients in the HR+ subgroup (median, 38.5 months; 95\% Cl, 30.1-46.9 months; $p<0.0001$ ).

Conclusions: The response to palliative AC chemotherapy did not differ among breast cancer subtypes. Despite chemosensitivity for palliative AC, the TN subtype has a shorter overall survival than non-TN subtypes. Innovative treatment strategies should be developed to slow the course of disease.
\end{abstract}

\section{Background}

Breast cancer encompasses a heterogeneous group of diseases at the molecular level [1-4], and can be classified into at least five distinct subtypes by gene expression profiling: luminal $\mathrm{A}$, luminal $\mathrm{B}$, normal breast-like, ERBB2, and basal like [5-10]. Basal cell-like tumors typically show low or no expression of HER2 and estrogen receptor (ER), and high expression of genes characteristic of basal epithelial cells $[1,4,11-13]$. These tumors

\footnotetext{
* Correspondence: ajis@skku.edu

'Division of Hematology-Oncology, Department of Medicine, Samsung Medical Center, Sungkyunkwan University School of Medicine, 50 Irwondong Gangnam-gu, Seoul 135-710 Korea

Full list of author information is available at the end of the article
}

may share clinical and biologic properties with triple negative breast cancers (TNBCs) that lack expression of ER, progesterone receptor (PgR) and HER2 [5-8]. There is increasing evidence that breast cancer molecular subtypes differ in their responses to therapeutic agents. TNBC is considered a high-risk subtype because of its typically younger patient age, poorly differentiated tumor characteristics, and shortened survival of patients who often do not benefit from targeted therapies [11-19]. Because there is insufficient data on which to base treatment selection, no specific systemic treatment strategy is currently recommended for the treatment of TNBC. 
Anthracyclines are some of the most widely used and effective drugs to treat patients with breast cancer in the adjuvant setting, as well as for patients with metastatic disease [20-25]. However, cumulative cardiotoxicity is a major limitation to the therapeutic use of anthracyclines and can lead to potentially fatal congestive heart failure [26-28]. Nevertheless anthracyclines are still the most widely used chemotherapeutic agents for the treatment of breast cancer. Because of their wide use and proven efficacy, anthracyclines may be especially important for the treatment of TNBCs that are known to lack specific therapeutic targets. Doxorubicin shows pre-clinical and clinical activity against BRCA1-associated cancers, a closely related group of diseases with significant morphologic, phenotypic, and genetic overlap with TNBCs $[29,30]$. This further suggests the potential of anthracycline chemotherapy as a therapeutic option for TNBCs.

Given the interest in using doxorubicin for treating patients with $\mathrm{TN}$ tumors, we have retrospectively reviewed the medical records of metastatic breast cancer patients who received combination chemotherapy with doxorubicin and cyclophosphamide (AC) as a first line treatment. The aim of this study was to evaluate the efficacy of AC combination therapy in patients with TNBC. In addition, we characterized the clinicopathologic findings relating to the response to $\mathrm{AC}$ chemotherapy.

\section{Methods}

\section{Patients}

We performed a retrospective analysis of medical records of patients with metastatic or recurrent breast cancer who received AC combination chemotherapy as a first-line treatment at Samsung Medical Center between January 2001 and December 2006. These studies were approved by the Samsung Medical Center Institutional Review Board.

\section{Immunohistochemistry and molecular classification}

All pathologic specimens were reviewed by two experienced pathologists who determined the status of ER, PgR, and HER2 using immunohistochemical (IHC) techniques. According to the Allred scoring system, ER and PgR negativity was defined as a total score from $0-2$ by IHC using antibodies to the ER (Immunotech, France) and PgR (Novocastra, UK). According to National Comprehensive Cancer Network (NCCN) guidelines, HER2 was assessed using IHC techniques (DAKO, Santa Barbara, CA, USA) and/or fluorescence in situ hybridization (FISH). IHC grades 0 and 1 were defined as a negative result for HER2, and the lack of HER2 amplification was confirmed by FISH if HER2 was rated $2+$ by IHC. "Triple negativity" was defined as a lack of expression of ER,
PgR, and HER2. The HER2+ subtype was defined as HER2-positive with ER- and PR-negative, while hormone receptor-positive was defined as ER- and/or PRpositive, regardless of HER2-positivity subtypes. Ki-67 growth fractions and p53 status were assessed using antibodies: Ki-67 (DACO, Glostrup, Denmark), and p53 (1:80, Zymed, San Francisco, CA, USA). The percentage of positive nuclei stained for Ki-67 was calculated for each section based on approximately 1,000 carcinoma cell nuclei. High proliferative index was defined as $50 \%$ or more stained nuclei. Immunoreactivity of p53 was defined as greater than $5 \%$ of cells having distinct nuclear staining.

\section{Statistical analysis}

The treatment response to AC was evaluated by reviewing imaging studies according to the Response Evaluation Criteria in Solid Tumors (RECIST). AC chemotherapy was doxorubicin $60 \mathrm{mg} / \mathrm{m}^{2}$ plus cyclophosphamide 600 $\mathrm{mg} / \mathrm{m}^{2}$ every 3 weeks. Progression-free survival (PFS) was defined as the time from the initial date of $\mathrm{AC}$ chemotherapy to the date that progressive disease was first documented. Overall survival (OS) was defined as the time from the initial date of AC chemotherapy to the date of death from any cause, or the date of last followup. The calculation was performed using the KaplanMeier method. The log-rank method (also known as the Mantel-Cox test) was used to compare survival rates. The differences in responses between subtypes were estimated by the $\chi^{2}$ test or Fisher's exact test. A p $<0.05$ was considered significant.

\section{Results \\ Patient cohort}

Between January 2001 and December 2006, 124 patients with metastatic breast cancer were treated with palliative $\mathrm{AC}$ as a first-line treatment at Samsung Medical Center. Immunohistochemical data for ER, PgR, and HER2 status were available for 110 of these patients. Among them, sixty-eight patients relapsed after surgery for invasive breast cancers, and forty-two patients had metastatic diseases at diagnoses.

Subgroups were classified on the basis of ER, PR, and HER2 IHC findings with 71 of the 110 patients $(64.5 \%)$ being $\mathrm{HR}+, 14$ patients (12.7\%) HER2+, and 25 patients (22.7\%) TN. The median age at diagnosis was 45 years (range, 24-69 years). Median disease free intervals (DFI) after surgery among relapsed patients were 47.6 months for $\mathrm{HR}+, 40.6$ months for HER2+, and 38.7 months for TNBC ( $\mathrm{p}=0.231)$. Forty patients $(36.4 \%)$ were initially diagnosed with metastatic disease. TNBCs showed poorer histologic differentiation (Bloom-Richardson pathologic grade III: $87.5 \%$ for TNBC, $25.0 \%$ for HER2+, 
and $37.8 \%$ for $\mathrm{HR}+$, respectively; $\mathrm{p}=0.001$ ) and a higher proliferative index (Ki-67 >50\%: 85.7\% for TNBC, $0 \%$ for HER $2+$, and $31.3 \%$ for $\mathrm{HR}+$, respectively; $\mathrm{p}=0.013$ ) than HER2+ or HR+ subtypes. Other clinical features, such as age, stage at diagnosis, and previous treatment did not differ significantly among the three subtypes. Adjuvant doxorubicin was administered to 7 patients (6 in $\mathrm{HR}+, 1$ in HER2+). Hepatic metastases were more common in the HER2+ subgroup $(52.4 \%$ for $\mathrm{HR}+$, $84.6 \%$ for HER $2+, 45.5 \%$ for TNBC; $\mathrm{p}=0.046$ ). Adjuvant endocrine treatment was performed for $43 \mathrm{HR}+$ patients (Table 1). Next to AC chemotherapy, median numbers of palliative chemotherapy regimens were 3 for $\mathrm{HR}+, 2$ for HER2+, and 1 for TNBC $(\mathrm{p}=0.006)$. Endocrine treatment was treated for $17 \mathrm{HR}+$ patients $(24 \%)$ as palliative aim (Table 1).

\section{Treatment responses}

Of the 110 patients, 105 (95\%) with measurable lesions had a clinical response. Two of these 105 patients had a complete response (CR), and 56 patients achieved a partial response (PR; Table 2). Both patients with CR were $\mathrm{HR}+$. The overall response rate (ORR) of 105 patients with measurable disease was $54.3 \%$. The ORR of HER2+ patients was slightly lower than those of patients with $\mathrm{HR}+$ or TN-subtypes, but this difference was not statistically significant $(42.9 \%, 55.9 \%$, and $56.5 \%$, respectively; $\mathrm{p}=0.542$; Table 2).

\section{Survival analysis}

Progression-free survival (PFS)

The median PFS to AC chemotherapy was 9.5 months (95\% CI, 7.1-11.9 months). The median PFS of each

Table 1 Clinicopathologic characteristics of patients according to subtypes

\begin{tabular}{|c|c|c|c|c|}
\hline & $\mathrm{HR}+(\mathrm{N}=71)$ & HER2 + $(N=14)$ & $\mathrm{TN}(\mathrm{N}=25)$ & $P$ value \\
\hline \multicolumn{5}{|l|}{ Clinical characteristics at initial diagnosis } \\
\hline Median age & $43.8(30-69)$ & $49.5(33-65)$ & $47.0(24-77)$ & $.398^{A}$ \\
\hline \multicolumn{5}{|l|}{ Initial stage } \\
\hline 1 & $9(12.7 \%)$ & $1(7.1 \%)$ & $2(8.0 \%)$ & \\
\hline$\|$ & $23(32.4 \%)$ & $4(28.6 \%)$ & $11(44.0 \%)$ & \\
\hline III & $11(15.5 \%)$ & $2(14.3 \%)$ & $2(8.0 \%)$ & \\
\hline IV & $25(35.2 \%)$ & $6(42.9 \%)$ & $9(36.0 \%)$ & $.951^{B}$ \\
\hline unknown & $3(4.2 \%)$ & $1(7.1 \%)$ & $1(4.0 \%)$ & \\
\hline Familial History & $16(23.5 \%)$ & $4(28.6 \%)$ & $7(29.2 \%)$ & $.829^{B}$ \\
\hline DFI after surgery (median) & 47.6 months & 40.6 months & 38.7 months & 0.231 by log-rank test \\
\hline \multicolumn{5}{|l|}{ Tumor characteristics } \\
\hline B-R.Gr. III $(n=69)$ & $17(37.8 \%)$ & $2(25.0 \%)$ & $14(87.5 \%)$ & $* .001^{B}$ \\
\hline$P 53<5 \%(n=93)$ & $32(55.2 \%)$ & $7(50.0 \%)$ & $9(42.9 \%)$ & $.621^{B}$ \\
\hline Ki $67>50 \%(n=25)$ & $5(31.3 \%)$ & $0(0 \%)$ & $6(85.7 \%)$ & ${ }^{*} .013^{B}$ \\
\hline \multicolumn{5}{|l|}{ Previous (neoadjuvant or adjuvant) treatments } \\
\hline Curative surgery. & $45(63.4 \%)$ & $8(57.1 \%)$ & $15(60.0 \%)$ & $.888^{B}$ \\
\hline Neoadju-CTx & $3(4.2 \%)$ & $0(0 \%)$ & $1(4.0 \%)$ & $.573^{B}$ \\
\hline Adjuvant CTx & $35(49.3 \%)$ & $7(50.0 \%)$ & $12(48.0 \%)$ & $.991^{B}$ \\
\hline Adjuvant doxorubicin & $6(17.1 \%)$ & $1(14.3 \%)$ & $0(0 \%)$ & $.048^{B}$ \\
\hline Adjuvant HormoTx & $43(60.6 \%)$ & 0 & 0 & $<0.0001^{B}$ \\
\hline \multicolumn{5}{|l|}{ Distant Metastases } \\
\hline Lung & $49(74.2 \%)$ & $11(84.6 \%)$ & $15(62.5 \%)$ & 0.316 \\
\hline Pleura & $41(57.8 \%)$ & $8(57.4 \%)$ & $10(45.5 \%)$ & 0.216 \\
\hline Liver & $33(52.4 \%)$ & $11(84.6 \%)$ & $10(45.5 \%)$ & 0.046 \\
\hline Brain & $11(17.7 \%)$ & $3(23.1 \%)$ & $6(27.3 \%)$ & 0.629 \\
\hline Bone & $36(50.7 \%)$ & $8(57.1 \%)$ & $10(40.0 \%)$ & 0.283 \\
\hline Skin & $14(19.7 \%)$ & $1(7.1 \%)$ & $9(36 \%)$ & 0.081 \\
\hline Soft tissue & $22(31.0 \%)$ & $1(7.1 \%)$ & $6(24.0 \%)$ & 0.120 \\
\hline \multicolumn{5}{|l|}{ Next treatment after AC chemotherapy } \\
\hline Median number of CTx (range) & $3(0-11)$ & $2(0-8)$ & $1(0-7)$ & 0.006 \\
\hline Number of patients with HormoTx (\%) & $17(24 \%)$ & 0 & 0 & 0.001 \\
\hline Number of patients with trastuzumab Tx (\%) & $5(7.0 \%)$ & $4(28.6 \%)$ & 0 & 0.009 \\
\hline
\end{tabular}

$\mathrm{DFI}$, disease free interval; CTx, chemotherapy; HormoTx, hormonal therapy; Tx, treatment.

${ }^{A}$ Continuous variables; One way ANOVA.

${ }^{B}$ Categorical variables; Pearson's chi-square test. 
Table 2 Treatment Response According to Subtypes ( $n=105$ patients with measurable diseases)

\begin{tabular}{|c|c|c|c|c|c|}
\hline & Total $(n=105)$ & $H R(n=68)$ & HER2 $(n=14)$ & TN $(n=23)$ & $p$ \\
\hline Median cycles & $6.0(1-12)$ & $5.9(1-12)$ & $4.8(1-9)$ & $5.6(1-9)$ & 0.454 \\
\hline \multicolumn{6}{|l|}{ Response } \\
\hline$C R$ & 2 & 2 & 0 & 0 & \\
\hline PR & 55 & 36 & 6 & 13 & \\
\hline SD & 25 & 19 & 3 & 4 & \\
\hline PD & 20 & 11 & 4 & 5 & \\
\hline Not evaluable & 2 & 0 & 1 & 1 & \\
\hline Overall response rate & 57 (54.3\%) & 38 (55.9\%) & $6(42.9 \%)$ & $13(56.5 \%)$ & 0.542 \\
\hline
\end{tabular}

CR; complete response, PR; partial response, SD; stable disease, PD; progressive disease.

phenotype was 8.1 months for TN (95\% CI, 7.2-9.1 months), 9.1 months for HER2+ (95\% CI, 1.3-16.8 months), and 11.5 months for HR+ (95\% CI, 7.2-15.9 months; $\mathrm{p}=0.0002$ by log-rank test; Figure $1 \mathrm{~A}$ ).

\section{Overall survival}

With a median 55.8 months of follow-up (range, 29.2101.5 months), the median OS of all 110 patients was 32.4 months (95\% CI, 28.5-36.3 months). The median OS was 25.4 months (95\% CI, 17.9-32.9 months) in the TN subgroup and 27.3 months $(95 \% \mathrm{CI}, 9.3-45.3$ months) in the HER2+ subgroup. The median OS for these two groups was significantly shorter than OS for $\mathrm{HR}+$ patients (median, 38.5 months; 95\% CI, 30.3-46.7 months; $\mathrm{p}<0.0001$ ). Most of the HER2+ patients did not receive trastuzumab as first-line treatment with chemotherapy (Figure 1B).

Time-to-Death (TTD) from the end of AC chemotherapy

There is a significant difference between patients with TN and non-TN phenotypes in terms of TTD after AC chemotherapy (median TTD 15.9 months, 95\% CI, 7.823.9 months for TN; median TTD 13.2 months, $95 \% \mathrm{CI}$, 9.7-16.7 months for HER2+; median TTD 24.8 months; 95\% CI, 21.7-36.70 months for HR+; p < 0.0001). After
AC chemotherapy, most of the patients were treated with additional $2^{\text {nd }}$ or more lines of chemotherapies with various regimens including platinum and taxane agents. A median of three additional lines of palliative chemotherapies were undertaken for $\mathrm{HR}+$ patients, whereas a median of two lines and one line of chemotherapies were performed for HER2+ and TNBC patients, respectively $(\mathrm{p}=0.006) .17$ of $71(24 \%)$ of $\mathrm{HR}+$ patients were treated with palliative endocrine treatment. 9 of 14 HER2+ patients received palliative trastuzumab treatment with or without other cytotoxic agents. Multivariate analysis for survival

The TN phenotype and HER2 positivity were identified as independent prognostic factors for survival in Coxregression multivariate analysis (hazard ratio [HR] 2.03, $\mathrm{p}=0.011$ for TN; HR $1.86, \mathrm{p}=0.027$ for HER2 positivity) (Table 3 ).

\section{Discussion}

The present study demonstrates that TNBC has a similar response rate to AC combination chemotherapy compared to other subtypes (Table 2). This encouraging result is in agreement with published data regarding

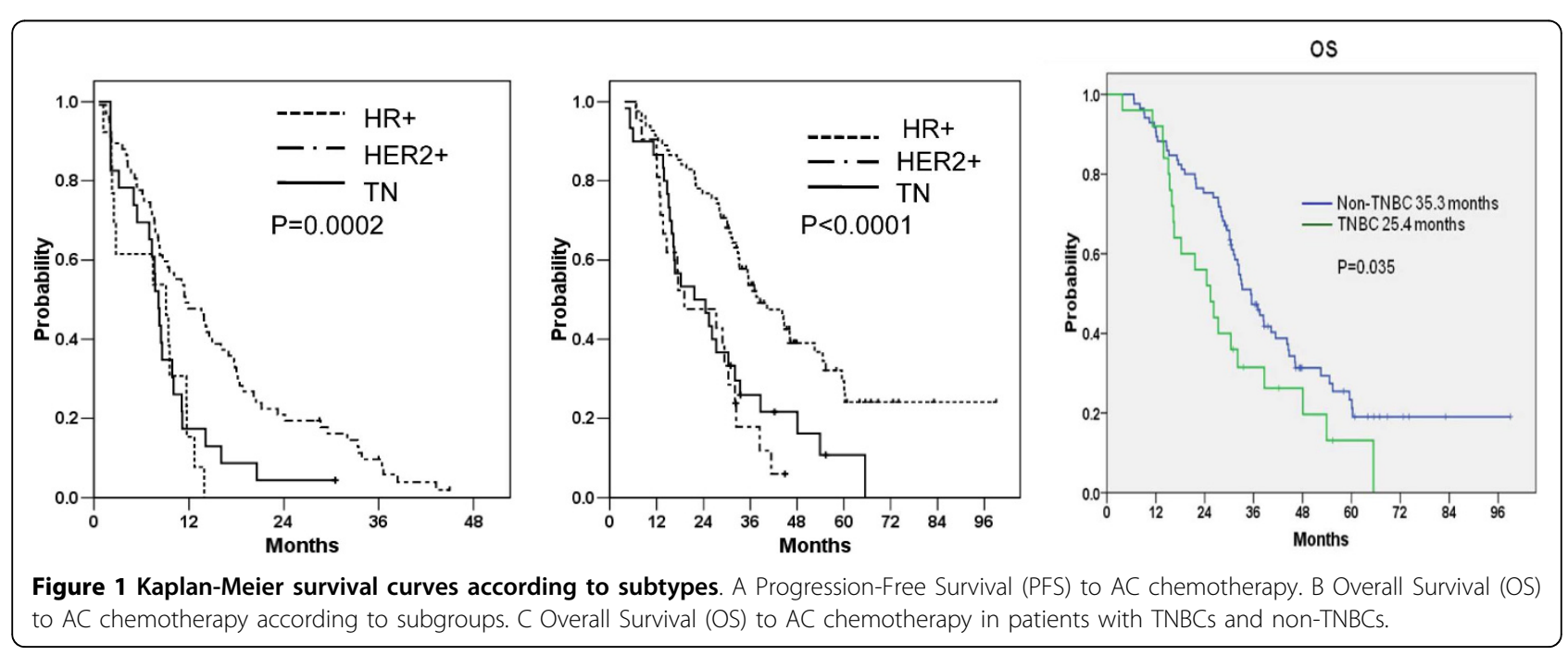


Table 3 Multivariate Cox-regression analysis on metastatic OS

\begin{tabular}{lcccc}
\hline & P value & Hazard Ratio (HR) & \multicolumn{2}{c}{$\mathbf{9 5 \%} \mathbf{C l}$} \\
\hline Triple negativity & 0.011 & 2.03 & 1.17 & 3.51 \\
HER2 positivity & 0.027 & 1.86 & 1.07 & 3.22 \\
\hline
\end{tabular}

OS: overall survival, $95 \% \mathrm{Cl}$ : 95\% confidence interval.

chemotherapy for TNBCs, irrespective of the chemotherapy regimen [31-33]. Despite the initial sensitivity to chemotherapy, several studies have shown that TNBCs carry a poor prognosis [11-13]. Our results also showed that TNBCs had poorer PFS and OS than nonTNBCs (Figure 1C). This finding suggests that despite the beneficial response to treatment, chemotherapy did not improve subsequent long-term survival of TNBC patients. Several studies support this paradoxical feature of high response, but poor long-term outcome [3,4,32-34].

Chemotherapy responsiveness is usually positively correlated with good clinical outcomes resulting in longterm survival [35]. However, this chemosensitivity is insufficient to overcome biologic aggressiveness, and rapid tumor-growth characteristics of TNBCs. In fact, the TTD after AC chemotherapy in patients with TNBCs was much shorter than that for $\mathrm{HR}+$ patients (median TTD, 15.9 months for TN, 13.2 months for HER2+, and 24.8 months for HR+; p = 0.0037). This finding suggests that another therapeutic strategy is needed to overcome the aggressive clinical behavior, prolong the survival time and improve the quality of life of TNBC patients. In contrast, a longer TTD after AC chemotherapy in patients with non-TNBCs, mainly of the HR+ subtype, may be due to the relatively slower tumor growth characteristics and additional benefit from hormonal therapies with subsequent easier disease control than for TNBCs. Thus, future treatment strategies should be developed based on the heterogeneity of the tumor. The consideration of such tumor heterogeneity will make a valuable contribution to the design of individualized therapy.

Dose intensification of conventional chemotherapeutic agents including doxorubicin may be beneficial to extend the therapeutic index [36]. However, most of the patients did not have durable responses. This suggests that doxorubicin resistance can easily occur in metastatic TNBC, perhaps due to prior exposure to doxorubicin or other chemotherapeutic agents in the adjuvant setting. Additionally, considering the poor correlation between chemosensitivity and long-term survival in patients with TNBCs, it is necessary to substantially prolong the response duration. This is because once lack of response occurs, TNBCs appears to follow a more aggressive and fatal clinical course TNBCs have more aggressive tumor biology as evidenced by a higher histological grade and higher expression of $\mathrm{Ki}-67$ than nonTNBCs. Recently, a few reports have suggested the potential use of these proliferation indexes as makers for complex tumor characteristics $[33,37,38]$. Importantly, TNBCs are composed of heterogeneous disease entities, consisting of two or more subtypes $[39,40]$.

The interpretation of our study may be limited, because it is a retrospective study. In addition, prior adjuvant therapy may affect on clinical outcomes in a metastatic setting. Despite these drawbacks, our study may have clinical impact in treating TNBC, for which therapeutic options are limited. The conventional treatments studies here need to be supplemented with new innovative therapeutic strategies based on an understanding of the biologic differences and aggressiveness of TNBCs. As HER2 direct therapy in HER2 positive subtype, new innovative targets for TNBC need to be developed. Ongoing clinical trials may open the door to better treatment outcomes. These trials evaluating new drugs such as PARP1 inhibitors [40-42], EGFR tyrosine kinase inhibitors [43], and antiangiogenic agents for TNBCs in adjuvant and palliative settings.

\section{Conclusions}

TNBC had a comparable response rate to first-line AC chemotherapy compared to non-TNBC. Nonetheless, TNBC patients had shorter survival than non-TNBC patients. Innovative therapeutic strategies are needed to overcome the biologic aggressiveness of TNBCs.

\section{Acknowledgements \\ Supported by a grant of the Korean Health 21 R\&D Project, Ministry of Health and Welfare, Republic of Korea (0412-CR01-0704-0001)}

\section{Author details}

${ }^{1}$ Division of Hematology-Oncology, Department of Medicine, Samsung Medical Center, Sungkyunkwan University School of Medicine, 50 Irwondong Gangnam-gu, Seoul 135-710 Korea. '2Department of Pathology, Samsung Medical Center, Sungkyunkwan University School of Medicine, 50 Irwon-dong Gangnam-gu, Seoul 135-710 Korea.

\section{Authors' contributions}

SYY carried out raw data and primary statistical analyses. JSA planned basic design of the study and coordination. JEU, DHL, and SHJ participated in data analysis and draft writing. HJJ, KHK, MHC, and MJP participated in clinical data collection and assisted statistical analysis. EYC and YLC carried out the immunohistochemical staining and evaluated the immunostaining. YHP participated in writing the manuscript and coordination. YHI organized and supervised the study. All authors read and approved the final manuscript.

\section{Competing interests}

The authors declare that they have no competing interests.

Received: 1 October 2009 Accepted: 5 October 2010

Published: 5 October 2010

\section{References}

1. Dinh $\mathrm{P}$, Sotiriou $\mathrm{C}$, Piccart MJ: The evolution of treatment strategies: Aiming at the target. Breast 2007, 16(suppl 2):S10-S6. 
2. Desmedt C, Haibe-Kains B, Wirapati P, Buyse M, Larsimont D, Bontempi G, Delorenzi M, Sortiriou C: Biological processes associated with breast cancer clinical outcome depend on the molecular subtypes. Clin Cancer Res 2008, 14:5158-5165.

3. Rouzier R, Perou CM, Symmans WF, Ibrahim N, Cristofanilli M, Anderson K. Hess KR, Stec J, Ayers M, Wagner P, Morandi P, Fan C, Rabiul I, Ross JS, Hortogagyi GN, Pusztai L: Breast cancer molecular subtypes respond differently to preoperative chemotherapy. Clin Cancer Res 2005, 11:5678-5685.

4. Carey LA, Dees EC, Sawyer L, Gatti L, Moore DT, Collichio F, Ollila DW, Sartor Cl, Graham ML, Perou CM: The triple negative paradox: Primary tumor chemosensitivity of breast cancer subtypes. Clin Cancer Res 2007 13:2329-2334.

5. Perou CM, Sørlie T, Eisen MB, van de Rijn M, Jeffrey SS, Rees CA, Pollack JR, Ross DT, Johnsen H, Akslen LA, Fluge O, Pergamenschikov A, Williams C Zhu SX, Lønning PE, Børresen-Dale AL, Brown PO, Botstein D: Molecular portraits of human breast tumours. Nature 2000, 406:747-752.

6. Sørlie T, Perou CM, Tibshirani R, Aas T, Geisler S, Johnsen H, Hastie T, Eisen MB, van de Rijn M, Jeffrey SS, Thorsen T, Quist H, Matese JC, Brown PO, Botstein D, Eystein Lønning P, Børresen-Dale AL: Gene expression patterns of breast carcinomas distinguish tumor subclasses with clinical implications. Proc Natl Acad Sci USA 2001, 98:10869-10874.

7. Sørlie T, Tibshirani R, Parker J, Hastie T, Marron JS, Nobel A, Deng S, Johnsen H, Pesich R, Geisler S, Demeter J, Perou CM, Lønning P, Brown PO, Børresen-Dale AL. Botstein D: Repeated observation of breast tumor subtypes in independent gene expression data sets. Proc Natl Acad Sci USA 2003, 100:8418-8423.

8. Sotiriou C, Neo SY, McShane LM, Korn EL, Long PM, Jazaeri A, Martiat P, Fox SB, Harris AL, Liu ET: Breast cancer classification and prognosis based on gene expression profiles from a population based study. Proc Nat Acad Sci USA 2003, 100:10393-10398.

9. Carey LA, Perou CM, Livasy CA, Dressler LG, Cowan D, Conway K, Karaca G, Troester MA, Tse CK, Edmiston S, Deming SL, Geradts J, Cheang MC, Nielsen TO, Moorman PG, Earp HS, Millikan RC: Race, breast cancer subtypes, and survival in the Carolina Breast Cancer Study. JAMA 2006, 295:2492-2502.

10. Chia K, Tutt A: Triple negative breast cancer: an update. Adv Breast Cancer 2007, 4(3):75-80

11. Dent R, Trudeau M, Pritchard KI, Hanna WM, Kahn HK, Sawka CA, Lickley LA, Rawlinson E, Sun P, Narod SA: Triple-negative breast cancer: clinical features and patterns of recurrence. Clin Cancer Res 2007, 13:4429-4434.

12. Bauer KR, Brown M, Cress RD, Parise CA, Caqqiano V: Descriptive analysis of estrogen receptor (ER)-negative, progesterone receptor (PR)-negative, and HER2-negative invasive breast cancer, the so-called triple-negative phenotype: a population-based study from the California cancer Registry. Cancer 2007, 109(9):1721-1728.

13. Kilburn LS, the TNT trial management group: 'Triple negative' breast cancer: a new area for phase III breast cancer clinical trials. Clin Oncol ( $R$ Coll Radio) 2008, 20(1):35-39.

14. Rakha EA, El-Sayed ME, Green AR, Lee AH, Robertson JF, Ellis IO: Prognostic markers in triple-negative breast cancer. Cancer 2007, 109(1):25-32.

15. Turner N, Tutt A, Ashworth A: Hallmarks of 'BRCAness' in sporadic cancers. Nat Rev Cancer 2004, 4(10):814-819.

16. Diaz LK, Cryns VL, Symmans WF, Sneige N: Triple negative breast carcinoma and the basal phenotype: from expression profiling to clinical practice. Adv Anat Pathol 2007, 14(6):419-430.

17. Reis-Filho JS, Tutt AN: Triple negative tumours: a critical review. Histopathology 2008, 52:108-118.

18. Irvin WJ Jr, Carey LA: What is triple-negative breast cancer? Eur J Cancer 2008, 44:2799-2805.

19. A'Hern RP, smith IE, Ebbs RS: Chemotherapy and survival in advanced breast cancer: the inclusion of doxorubicin in Cooper type regimens. $\mathrm{Br}$ J Cancer 1993, 67:801-805.

20. Fossati R, Confalonieri C, Torri V, Ghislandi E, Penna A, Pistotti V, Tinazzi A, Liberati A: Cytotoxic and hormonal treatment for metastatic breast cancer: a systemic review of published randomized trials involving 31,510 women. J Clin Oncol 1998, 16:3439-3460.

21. Green JA, Slater AJ, Campbell IR, Kelly V: Advanced breast cancer: a randomized study of doxorubicin or mitoxantrone in combination with cyclophosphamide and vincristine. Breast Cancer Res Treat 1996, 39:155-163.
22. Bernett JM, Muss HB, Doroshow JH, Wolff S, Krementz ET, Cartwright K, Dukart G, Reisman A, Schoch I: A randomized multicenter trial comparing mitoxantrone, cyclophosphamide, and fluorouracil with doxorubicin, cyclophosphamide, and fluorouracil in the therapy of metastatic breast carcinoma. J Clin Oncol 1988, 6:1611-1620.

23. Henderson IC, Allegra JC, Woodcock T, Wolff S, Bryan S, Cartwright K, Dukart G, Henry D: Randomized clinical trial comparing mitoxantrone with doxorubicin in previously treated patients with metastatic breast cancer. J Clin Oncol 1989, 7:560-571.

24. Crown J, Diéras V, Kaufmann M, von Minckwitz G, Kaye S, Leonard R, Marty M, Misset JL, Osterwalder B, Piccart M: Chemotherapy for metastatic breast cancer - report of a European expert panel. Lancet Oncol 2002, 3:719-726.

25. Pai VB, Nahata MC: Cardiotoxicity of chemotherapeutic agents: incidence, treatment and prevention. Drug Saf 2000, 22:263-302.

26. Von Hoff DD, Layard MW, Basa P, Davis HL Jr, Von Hoff AL, Rozencweiq M, Muqqia FM: Risk factors for doxorubicin-induced congestive heart failure. Ann Intern Med 1979, 91:710-717.

27. Hershman DL, Shao T: Anthracycline cardiotoxicity after breast cancer treatment. Oncology 2009, 23(3):227-234.

28. Barrett-Lee PJ, Dixon JM, Farrell C, Jones A, Leonard R, Murray N, Palmieri C, Plummer CJ, Stanley A, Verrill MW: Expert opinion on the use of anthracyclines in patients with advanced breast cancer at cardiac risk. Ann Oncol 2009, 20(5):816-827.

29. Kennedy RD, Quinn JE, Mullan PB, Johnston PG, Harkin DP: The role of BRCA1 in the cellular response to chemotherapy. J Natl Cancer Inst 2004 96(22):1659-1668.

30. Byrski T, Gronwald J, Huzarski T, Grzybowska E, Budryk M, Stawicka M, Mierzwa T, Szwiec M, Wiśniowski R, Siolek M, Narod SA, Lubinski J, Polish Hereditary Breast Cancer Consortium: Response to neo-adjuvant chemotherapy in women with BRCA1-positive breast cancers. Breast Cancer Res Treat 2008, 108:289-296.

31. Sirohi B, Arnedos M, Popat S, Ashley S, Nerukar A, Walsh G, Johnston S, Smith IE: Platinum-based chemotherapy in triple-negative breast cancer. Ann Oncol 2008, 19:1847-1852.

32. Keam B, Im SA, Kim HJ, Oh DY, Kim JH, Lee SH, Chie EK, Han W, Im DW, Moon WK, Kim KY, Park IA, Noh DY, Heo DS, Ha SW, Bang YJ: Prognostic impact of clinicopathologic parameters in stage II/III breast cancer treated with neoadjuvant docetaxel and doxorubicin chemotherapy: paradoxical features of the triple negative breast cancer. BMC Cancer 2007, 7:203

33. Hugh J, Hanson J, Cheang MC, Nielsen TO, Perou CM, Dumontet C, Reed J, Krajewska M, Treilleux I, Rupin M, Magherini E, Mackey J, Martin M, Vogel C: Breast cancer subtypes and response to docetaxel in node-positive breast cancer: use of an immunohistochemical definition in the BCIRG001 trial. J Clin Onol 2009, 27:1168-1176

34. Uhm JE, Park YH, Yi SY, Cho EY, Choi YL, Lee SJ, Park MJ, Lee SH, Jun HJ, Ahn JS, Kang WK, Park K, Im YH: Treatment outcomes and cliniopathologic characteristics of triple-negative breast cancer patients who received platinum-containing chemotherapy. Int J Cancer 2009, 124:1457-1462.

35. Marty M, Espie M, Cottu PH, Cuvier C, Lerebours F: Optimizing chemotherapy for patients with advanced breast cancer. Oncology 1999 57:21-26.

36. Gluz O, Nitz UA, Harbeck N, Ting E, Kates R, Lindemann W, Jackisch C, Berdel WE, Kirchner H, Metzner B, Werner F, Schütt G, Frick M, Poremba C, Diallo-Danebrock R, Mohrmann S: Triple-negative high-risk breast cancer derived particular benefit from dose intensification of adjuvant chemotherapy: results of WSG AM-01 trial. Ann Oncol 2008, 19:861-870.

37. Jones C, Ford E, Gillett C, Ryder K, Merrett S, Reis-Filho JS, Fulford LG, Hanby A, Lakhani SR: Molecular cytogenetic identification of subgroups of grade III invasive ductal breast carcinomas with different clinical outcomes. Clin Cancer Res 2004, 10:5988-5997.

38. Livasy CA, Karaca G, Nanda R, Tretiakova MS, Olopade Ol, Moore DT, Perou CM: Phenotypic evaluation of the basal-like subtype of invasive breast carcinoma. Mod Pathol 2006, 19:264-271.

39. Cheang MC, Voduc D, Bajdik C, Leung S, McKinney S, Chia SK, Perou CM, Nielson TO: Basal-like breast cancer defined by five bio-marker has superior prognostic value than triple-negative phenotype. Clin Cancer Res $2008,14: 1368-1376$. 
40. Sasa M, Bando Y, Takahashi M, Hirose T, Nagao T: Screening for basal marker expression is necessary for decision of therapeutic strategy for triple-negative breast cancer. J Surg Oncol 2008, 97:30-34.

41. Tutt A, Robson M, Garber JE, Domchek S, Audeh MW, Weitzel JN, Friedlander M, Carmichael J: Phase II trial of the oral PARP inhibitor olaparib in BRCA-deficient advanced breast cancer. J Clin Oncol 2009, 27:803s, (abstract \# CRA501).

42. O'Shaughnessy J, Osborne C, Pippen J, Yoffe M, Patt D, Monaghan G, Rocha C, Ossovskaya V, Sherman B, Bradley C: Efficacy of BSI-201, a poly (ADP-ribose) polymerase-1 (PARP1) inhibitors in combination with gemcitabine/carboplatin $(G / C)$ in patients with metastatic triple-negative breast cancer (TNBC): Results of a randomized phase II trial. J Clin Oncol 2009, 27:793s, (abstract \# 3).

43. Carey LA, Rugo HS, Marcom PK, Irvin W, Ferraro M, Burrow E, He X,

Perou CM, Winer EP, TBCRC 001: EGFR inhibition with cetuximab added to carboplatin in metastatic triple-negative (basal-like) breast cancer. J Clin Oncol 2008, 26:43s, (abstract \# 1009).

\section{Pre-publication history}

The pre-publication history for this paper can be accessed here: http://www.biomedcentral.com/1471-2407/10/527/prepub

doi:10.1186/1471-2407-10-527

Cite this article as: Yi et al:: Favorable response to doxorubicin combination chemotherapy does not yield good clinical outcome in patients with metastatic breast cancer with triple-negative phenotype. BMC Cancer 2010 10:527.

\section{Submit your next manuscript to BioMed Central and take full advantage of:}

- Convenient online submission

- Thorough peer review

- No space constraints or color figure charges

- Immediate publication on acceptance

- Inclusion in PubMed, CAS, Scopus and Google Scholar

- Research which is freely available for redistribution

Submit your manuscript at www.biomedcentral.com/submit 